\title{
Higher Activity of Alcohol Dehydrogenase Is Correlated with Hepatic Fibrogenesis
}

\author{
$\mathrm{Na}$ Gao, Jing Li, Ming-Rui Li, Bing Qi, Zhao Wang, Gao-Ju Wang, Jie Gao, \\ and Hai-Ling Qiao
}

Institute of Clinical Pharmacology, School of Medicine, Zhengzhou University, Zhengzhou, China

Received March 29, 2018; accepted September 5, 2018

\begin{abstract}
Hepatofibrosis can progress to cirrhosis and hepatocellular carcinoma (HCC). Prevention, stabilization, and reversal of disease progression are vital for patients with hepatofibrosis, and identifying the risk factors for hepatofibrosis is urgently needed. In this study, we examined the activities of alcohol dehydrogenase $(\mathrm{ADH})$ and acetaldehyde dehydrogenase (ALDH) in the fibrotic livers of HCC patients $(n=88)$ and comparied these results with activities in patients with normal livers $(n=74)$. A fibrosis-carcinoma rat model was used to study the activity of $\mathrm{ADH}$ in fibrosis and HCC and the relationship between innate ADH activity and the extent of hepatofibrosis or HCC. Substantial interindividual variations were found in the activities of $A D H$ and $A L D H$ in normal livers. The activity levels of total ADH, $A D H I$, and $A D H I I$ in fibrotic livers were significantly higher than
\end{abstract}

those in normal livers $(P<0.001)$, whereas the activity of ALDH was slightly greater. The positive rates of $A D H I$ and $A D H I I$ were $84.1 \%$ and $77.3 \%$, respectively; the areas under the receiver operator characteristics (ROC) curve were 0.943 and 0.912, respectively. For the rat model compared with controls, ADH activity in liver was significantly increased at the fibrotic and HCC stages, and no significant difference was noted between $\mathrm{ADH}$ activity in the liver at these two stages. The innate activity of ADH in serum was well correlated with the extent of hepatofibrosis as indicated by Masson area $\%, \mathrm{Ki} 67^{+} \%$, proliferating cell nuclear antigen ${ }^{+} \%$, and GST-p average density at fibrotic stage but not at HCC stage. A higher level of activity of ADH is a risk factor for hepatofibrogenesis and might be a prevention target for hepatofibrosis.

\section{Introduction}

Hepatofibrosis, a common pathophysiology of chronic liver disease with various causes, leads to abnormal extracellular matrix deposition and ultimately to a pathologic process of liver structural and functional abnormalities (Wheeler et al., 2001; Bataller et al., 2004). Hepatofibrosis is mostly asymptomatic in its early stages, but as it progresses, it disrupts the liver architecture and function, ultimately leading to cirrhosis and even hepatocellular carcinoma (HCC) (Bataller et al., 2004). Early fibrosis is potentially reversible, but it has been widely accepted that liver cirrhosis is irreversible and has no effective therapeutic drug treatment. As the second leading cause of cancer-related death (Beck et al., 2017), HCC is a major global health problem. Prevention, stabilization, or reversal of disease progression is very important for patients with hepatofibrosis, and identification of the risk factors for hepatofibrosis is urgently needed.

Alcohol dehydrogenase (ADH) and acetaldehyde dehydrogenases (ALDH) are responsible for the metabolism of a variety

This work was supported by the National Natural Science Foundation of China (Grants 81473279 and 81673507) and Henan province key program of science and technology (Grant 162102310519) and Foundation for University Key Teacher by Henan province.

https://doi.org/10.1124/jpet.118.249425. of endogenous and exogenous substrates, including ethanol, retinol, aliphatic alcohols, hydroxysteroids, and lipid aldehyde (Song et al., 2015). Human ADH comprises a family of enzymes that have been grouped into several classes (Maly et al., 1999). In humans, the first two classes are located mainly in the hepatic parenchymal cells. ADH class I (ADHI) is the classic liver $\mathrm{ADH}$, representing up to $95 \%$ of the total activity in this organ, and ADH class II (ADHII) is detected only in the liver. Of all these isoenzymes, ADHI is the main one involved in ethanol metabolism. Isoenzymes of ADHI are dimers composed of $\alpha, \beta$, and $\gamma$ subunits, encoded by $A D H 1 A, A D H 1 B$, and $A D H 1 C$ loci (Maly et al., 1999). Some gene polymorphisms for $A D H 1 B$ and $A D H 1 C$, such as ADH1B polymorphism, have been reported to have a marginal effect on alcohol pharmacokinetics (Marshall et al., 2014). The metabolism of ethanol by $\mathrm{ADH}$ produces acetaldehyde, which is metabolized mainly by ALDH to acetate (Lieber, 1997; Zakhari and Li, 2007; Jelski and Szmitkowski, 2008). ALDH can be divided into groups according to their Michaelis constant values for acetaldehyde. Liver mitochondrial ALDHII is mainly responsible for the metabolism of acetaldehyde (Jelski and Szmitkowski, 2008).

According to the International Agency for Research on Cancer, acetaldehyde associated with the consumption of alcoholic beverages belongs to group 1 of human carcinogens. Acetaldehyde can interact with DNA to produce DNA adducts

ABBREVIATIONS: ADH, alcohol dehydrogenase; ALDH, acetaldehyde dehydrogenase; ALT, alanine aminotransferase; AST, aspartate aminotransferase; DEN, diethylnitrosamine; GST, glutathione-S-transferase placental form; HCC, hepatocellular carcinoma; PCNA, proliferating cell nuclear antigen; ROC, receiver operator characteristic; SMA, smooth muscle actin. 
(Yu et al., 2010). The acetaldehyde-DNA adducts can lead to cancer in many tissues, including the liver, esophagus, and gastrointestinal tract (Song et al., 2015). In addition, lack of $\mathrm{ADHIII}$ in hepatic stellate cells and natural killer cells has been associated with the inhibition of nonalcoholic hepatofibrosis (Yi et al., 2014). These results suggest that ADH is not only involved in alcohol-induced liver injury through the metabolism of ethanol but also may play a key role in nonalcoholic liver injury.

To date, a number of studies have focused on the relationship between ethanol-metabolizing enzymes (i.e., $\mathrm{ADHs}$ and $\mathrm{ALDHs}$ ) and disease, such as renal cell carcinoma, pancreatic cancer, and brain cancer (Jelski et al., 2007, 2008c, 2014; Laniewska-Dunaj et al., 2013; Orywal et al., 2015, 2016). Interestingly, total ALDH activity is not significantly changed in tissue or serum with these cancers; however, Jelski et al. (2008a) examined the change of ADH and ALDH activity in 44 cases of $\mathrm{HCC}$ and found that total ADH, $\mathrm{ALDH}$, and $\mathrm{ADHI}$ activities were significantly greater in $\mathrm{HCC}$ tissues than in healthy tissues. Jelski et al. (2008b) also reported that $\mathrm{ADHI}$ activity in serum was significantly increased in patients with metastatic liver cancer, but there was no change in ALDH activity. So far, changes in $\mathrm{ADH}$ activity in fibrotic livers have not yet been reported, nor have changes in $\mathrm{ADH}$ activity in serum and liver at different stages of HCC progression. Finally, as ADH and ALDH act sequentially on many substrates, knowledge of the ratio of $\mathrm{ADH}$ to $\mathrm{ALDH}$ (ADH/ALDH) is likely to be important.

To identify the risk factors for hepatofibrosis, our group obtained normal livers mainly from hepatic hemangioma patients and fibrotic livers from patients with HCC and measured the activities of total ADH, ADHI, ADHII, and ALDH. The fibrosis-carcinoma rat model induced by diethylnitrosamine (DEN) was used to study changes in the activity of $\mathrm{ADH}$ in different stages of HCC to determine whether high ADH activity was a risk factor for hepatofibrosis.

\section{Materials and Methods}

\section{Experiments with Human Livers}

Human Liver Samples. Human normal liver samples were obtained from 74 patients with normal liver function, and fibrotic liver tissues $2 \mathrm{~cm}$ distant from the tumor tissues were obtained from 88 patients with HCC between 2012 and 2014 (Gao et al., 2016, 2017; Zhou et al., 2016) (Table 1). All the liver samples were obtained at First Affiliate Hospital of Zhengzhou University, Affiliated Provincial People's Hospital of Zheng Zhou University, and Affiliated Cancer Hospital of Zhengzhou University. After excision, the liver samples were frozen in liquid nitrogen within 30 minutes. All patients signed informed consent forms, and this study was approved by the ethics committee of Zhengzhou University. Compared with the normal group, the HCC group comprised more men, smokers, and drinkers $(P<0.01)$.

Liver samples were assigned four stages from S1 to S4 (Zhou et al., 2016). Among the 88 fibrotic livers, 5 were S1, 15 were S2, 23 were S3, and 45 were $\mathrm{S} 4$.

Determination of ADH (Total ADH, ADHI, and ADHII) Activities and Total ALDH Activity. Liver tissues were homogenized in potassium phosphate buffer $(0.1 \mathrm{~mol} / \mathrm{liter}, \mathrm{pH} 7.4)$ and then centrifuged at $1200 \mathrm{~g}$ for 20 minutes at $4^{\circ} \mathrm{C}$. The supernatant was used to determine $\mathrm{ADH}$ and $\mathrm{ALDH}$ activities. The protein concentration was determined using a Bradford protein quantification kit and performed according to standard procedures provided by the manufacturer (BOSTER Biological Technology, Pleasanton, CA).

The activity of total ADH, ADHI, ADHII, and ALDH was measured according to the method of Skurský et al. (1979), Wierzchowski et al. (1989), and Jelski et al. (2008a). The activities of total ADH, ADHI, and ADHII were determined with $p$-nitrosodimethylaniline (NDMA),
TABLE 1

Demographic and laboratory data of normal and hepatocellular carcinoma (HCC) patients

S1: Portal area fibrosis expanded and confined in the hepatic sinus and lobule (5); S2: fibrosis around portal area, fibrous septa form, lobule structure maintained (15); S3: fibrous septums and lobule structure disorder, without cirrhosis (23); S4: early stage cirrhosis (45).

\begin{tabular}{|c|c|c|c|}
\hline & Normal & $\mathrm{HCC}$ & $P$ Value $^{a}$ \\
\hline \multicolumn{4}{|l|}{ Age (yr) } \\
\hline Average \pm S.D. & $49 \pm 11$ & $53 \pm 11$ & \\
\hline$\leq 44$ & 23 & 20 & \\
\hline $45-64$ & 45 & 51 & \\
\hline$>65$ & 6 & 17 & \\
\hline Gender & & & $<0.001$ \\
\hline Male & 24 & 75 & \\
\hline Female & 50 & 13 & \\
\hline Smoking & & & $<0.001$ \\
\hline Yes & 13 & 45 & \\
\hline No & 61 & 43 & \\
\hline Alcohol intake & & & $<0.01$ \\
\hline Yes & 12 & 32 & \\
\hline No & 62 & 56 & \\
\hline $\begin{array}{l}\text { Body mass index } \\
(\mathrm{BMI})^{b}\end{array}$ & $23.7 \pm 3.4$ & $24.2 \pm 3.0$ & \\
\hline Diagnosis & $\begin{array}{l}\text { Liver hemangioma, } \\
\text { metastatic carcinoma, } \\
\text { cholelithiasis, } \\
\text { gallbladder cancer }\end{array}$ & $\mathrm{HCC}$ & \\
\hline $\begin{array}{l}\text { Pathology } \\
\text { classification }\end{array}$ & Normal & $\mathrm{S} 1, \mathrm{~S} 2, \mathrm{~S} 3, \mathrm{~S} 4$. & \\
\hline Total & 74 & 88 & \\
\hline
\end{tabular}

${ }^{a}$ Gender, age, smoking status, and drinking habit had no significant effect on ADH, ADHI, ADHII, and ALDH activities $(P>0.05)$.

${ }^{b}$ Data of both height and weight of 44 patients in controls and 59 patients in HCC group were obtained and the BMI calculated.

4-methoxy-1-naphthaldehyde, and 6-methoxy-2-naphthaldehyde as substrates, and the activity of total ALDH was determined with 6-methoxy-2-naphthaldehyde as substrate. Briefly, the reaction mixture contained supernatant, substrate, NAD or NADH, and sodium phosphate buffer. A wavelength of $440 \mathrm{~nm}$ for total $\mathrm{ADH}$ and emission wavelengths of 370 and $360 \mathrm{~nm}$ with an excitation wavelength of $316 \mathrm{~nm}$ for ADHI and ADHII were used, respectively. An emission wavelength of $360 \mathrm{~nm}$ was used to determine the activity of ALDH; the excitation wavelength was $310 \mathrm{~nm}$.

\section{Experiments with Rats}

Establishment of Fibrosis-Carcinoma in a Rat Model. Fifty-one male Sprague-Dawley rats weighing $180 \pm 20 \mathrm{~g}$ were maintained at $22^{\circ} \mathrm{C}$ with a standard 12 -hour light/dark cycle with free access to rodent chow and tap water and were randomly divided into two groups: control $(n=10)$ and model $(n=41)$. After feeding, the model group was injected i.p. with $50 \mathrm{mg} / \mathrm{kg} \mathrm{DEN}$ twice weekly for 4 weeks and then injected i.p. with $50 \mathrm{mg} / \mathrm{kg}$ DEN once weekly to 14 weeks. Ding et al. (2017) reported that the HCC rat model induced by DEN was characterized by an inflammation stage (weeks 2-6), a fibrosis stage (weeks 8-12), and an HCC stage (weeks 14-20). In this experiment, 20 rats in the model group were randomly assigned and sacrificed at 12 weeks, designated the fibrosis group. The remaining rats in the model group were sacrificed at 19 weeks, and termed the HCC group. The control rats were injected intraperitoneally with normal saline and sacrificed at 19 weeks. The diagnoses of fibrosis and HCC were made based on the results of H\&E and Masson staining. The results were studied by a pathologist who was blinded to the study. Histopathologic examination showed centrilobular atypia and multiple larger dysplastic foci, and there was marked collagen deposition as demonstrated by Masson's trichrome staining in the rats treated with DEN for 12 weeks. In addition, about half of the rats developed HCC by week 19 according to pathology results. Our study was carried out in strict accordance with the Guide for the Care and Use of Laboratory Animals and all the 
experimental procedures reported here were approved by the Zhengzhou University Animal Care and Use Committee.

Serum from all rats was collected at 0,8 , and 12 weeks, and the sera of control and rats in HCC group were collected at 16 and 19 weeks. The livers were collected after sacrifice.

Preparation of Rat Liver Homogenates. Two hundred milligrams of liver tissue was homogenized in normal saline and then centrifuged at $2500 \mathrm{r} / \mathrm{min}$ for 10 minutes at $4^{\circ} \mathrm{C}$. The supernatant was used to determine enzyme activities. The protein concentration was determined by BCA protein quantification kit (BOSTER Biologic Technology).

Determination of Alanine Aminotransferase and Aspartate Aminotransferase (AST) in Serum. Alanine aminotransferase (ALT) and aspartate aminotransferase (AST) activity in serum was determined using a commercial assay kit from Jiancheng Bioengineering Institute (Nanjing, China) according to standard procedures. Results of serum AST and ALT activities are expressed as units per liter (U/liters).

Histopathology. Liver specimens for histopathological analysis were obtained from the tissues, fixed with $10 \%$ formalin, and embedded in paraffin. Paraffin sections, $5 \mu \mathrm{m}$ thick, were stained with H\&E and Masson staining. Liver specimens were graded according to the Ishak scoring system (Ishak et al., 1995). The percentage of fibrotic area after Masson staining was measured.

Immunohistochemistry. The altered hepatic foci (Kitahara et al., 1984; Sato et al., 1984) were measured by immunohistochemical analysis of glutathione-S-transferase placental form (GST-p) levels in the liver. Hepatocyte proliferation was quantified by immunohistochemical analysis of proliferating cell nuclear antigen (PCNA) and Ki-67. In addition, the activation of hepatic stellate cell was evaluated by immunohistochemical analysis of $\alpha$-smooth muscle actin (SMA) and collagen 1.

Anti-Ki67 antibody (ab 15580; Abcam, Cambridge, UK), anti-PCNA antibody (ab 29; Abcam), and anti-GST pi antibody (ab 138491; Abcam) were used for immunohistochemistry. The proportion of positive cells $\left(\mathrm{Ki}^{+} \%\right.$, $\left.\mathrm{PCNA}^{+} \%\right)$ and average density (GST-p) were quantified with image-processing software (Image-Pro Plus 6.0, Media Cybernetics, Rockville, MD). The expression of $\alpha$-SMA and collagen 1 was assessed by the H-score system (histochemistry score) (Yeo et al., 2015). Briefly, the formula for the H-score is as follows: $\mathrm{H}-\mathrm{SCORE}=\sum(\mathrm{PI} \times \mathrm{I})=$ (percentage of cells of weak intensity $\times 1$ ) + (percentage of cells of moderate intensity $\times 2$ ) + the percentage of cells of strong intensity $\times 3$ ).

Determination of the ADH Activity. The ADH activity in serum and liver homogenates of rats was determined using a commercial assay kit from Jiancheng Bioengineering Institute (Jiangsu, China) according to standard procedures.

\section{Statistical Analysis}

Statistical analysis was performed with SPSS 17.0 software (Rockville, MD). The data set of the human liver was not normally distributed; thus, the data were expressed as median and range, and nonparametric methods were generally used for statistical analyses. In the data set from the rat model, statistical differences between different stages were determined using an independent $t$ test or one-way analysis of variance since they were normally distributed. The Pearson correlation was used to determine the correlations between the activity of $\mathrm{ADH}$ and liver injury-related indexes. The level of the confidence was set at 0.05 .

\section{Results}

\section{ADH and ALDH Activities in Human Livers}

Activity of ADH and ALDH in Normal Human Livers. The activity of total $\mathrm{ADH}, \mathrm{ADHI}, \mathrm{ADHII}$, and total ALDH was detected in 74 normal liver samples using probe drugs known to be specific for each enzyme. The data for these measurements are shown in Table 2, and the results demonstrate substantial individual variations. The two greatest individual variations were evidenced in the activity of $\mathrm{ADH}$ and
TABLE 2

Activity of alcohol dehydrogenase (ADH) and acetaldehyde dehydrogenase (ALDH) in normal $(n=74)$ and fibrotic livers $(n=88)$

\begin{tabular}{|c|c|c|c|c|}
\hline & \multicolumn{2}{|c|}{$\begin{array}{l}\text { Normal Tissue (Median, Range) } \\
\left(\mathrm{nmol}^{-} \mathrm{min}^{-1} \cdot \mathrm{mg}^{-1} \text { protein) }\right.\end{array}$} & \multicolumn{2}{|c|}{$\begin{array}{l}\text { Fibrotic Tissue (Median, Range) } \\
\left(\mathrm{nmol} \cdot \mathrm{min}^{-1} \cdot \mathrm{mg}^{-1} \text { Protein }\right)\end{array}$} \\
\hline & Median, Range & Ratio & Median, Range & Ratio \\
\hline $\mathrm{ADH}$ & $1.81,0.16-72.12$ & 450.8 & $7.27,1.18-43.07^{a}$ & 36.5 \\
\hline $\mathrm{ADHI}$ & $0.44,0.09-1.26$ & 14.0 & $1.34,0.37-7.10^{a}$ & 19.2 \\
\hline ADHII & $0.18,0.03-0.53$ & 17.7 & $0.46,0.14-1.66^{a}$ & 11.9 \\
\hline $\mathrm{ALDH}$ & $0.12,0.02-0.32$ & 16.0 & $0.15,0.03-0.35^{b}$ & 11.7 \\
\hline $\mathrm{ADH} / \mathrm{ALDH}$ & $17.2,1.6-1295.3$ & 809.6 & $44.61,10.4-726.5^{a}$ & 69.9 \\
\hline ADHI/ALDH & $3.8,1.02-41.88$ & 41.1 & $8.96,1.90-49.21^{a}$ & 25.9 \\
\hline
\end{tabular}

${ }^{a}$ Versus normal tissues, $P<0.001$.

${ }^{b}$ Versus normal tissues, $P<0.01$.

$\mathrm{ADH} / \mathrm{ALDH}$, with 450.8 and 809.6-fold differences, followed by that of $\mathrm{ADHI} / \mathrm{ALDH}, \mathrm{ADHII}, \mathrm{ALDH}$, and $\mathrm{ADHI}$, demonstrating changes from 14- to 41-fold. The values for $\mathrm{ADH}$ activity at the 5th and the 95 th percentiles were 0.38 and $50.4 \mathrm{nmol} \cdot \mathrm{min}^{-1} \cdot \mathrm{mg}^{-1}$ protein, respectively, exhibiting about a 132 -fold variation. There were six outliers $(60.91,71.70,72.12,0.16,0.27$, and $0.34 \mathrm{nmol}$. $\mathrm{min}^{-1} \cdot \mathrm{mg}^{-1}$ protein) in total ADH activity.

No statistically significant differences $(P>0.05)$ were seen in the ADH, ADHI, ADHII, and ALDH activities as a function of gender, age, smoking status, or drinking habit (data not shown).

Activity of ADHs and ALDH in Fibrotic Livers. The median protein concentration in fibrotic livers was significantly lower than that in normal liver tissues $(P<0.05)$. Total $\mathrm{ADH}, \mathrm{ADHI}, \mathrm{ADHII}$, and ALDH activities were detected in 88 fibrotic livers and are shown in Table 2. Like in normal livers, there were substantial individual variations; the two greatest individual variations were observed in the activity of $\mathrm{ADH}$ and $\mathrm{ADH} / \mathrm{ALDH}$, which varied by 36.5- and 69.9-fold. The results show that individual variation is less than that in normal livers. The values of $\mathrm{ADH}$ activity at the 5th and the 95th percentiles were 1.9 and $18.8 \mathrm{nmol} \cdot \min ^{-1} \cdot \mathrm{mg}^{-1}$ protein, respectively, exhibiting about a 9.9 -fold variation. As with normal livers, no statistically significant differences $(P>0.05)$ were found in the ADH, ADHI, ADHII, and ALDH activities as a function of gender, age, smoking status, or drinking habit (data not shown).

Compared with normal livers, total levels of ADH, ADHI, and ADHII activity were significantly increased in fibrotic livers $(P<0.001)$, with $4.0-, 3.0-$, and 2.6 -fold changes. The ALDH activity in fibrotic livers was also greater than that of normal livers $(P<0.01)$, but the rate of increase was relatively small (i.e., 1.3-fold). The ratios of ADH/ALDH and ADH I/ALDH were also increased significantly in fibrotic livers relative to those of controls. These results suggested that fibrotic livers might have a greater capability for ethanol metabolism to acetaldehyde.

Correlation between the Activities of Total ADH, ADHI, ADHII, and ALDH. Correlations between the activities for total $\mathrm{ADH}, \mathrm{ADHI}$, and $\mathrm{ADHII}$ were analyzed. Positive correlation was shown for each of them in both normal tissue (Fig. 1A) and fibrotic tissue (Fig. 1B). Strong correlations $(r \geq$ $0.6)$ were observed between ADHI and ADHII in normal livers, and the remaining correlations were moderate $(0.3 \leq r<0.6)$. The activity of ALDH correlated only with ADHII, which participates actively in the degradation of circulating epinephrine and norepinephrine, in normal livers $(P<0.01)$. 
A-1

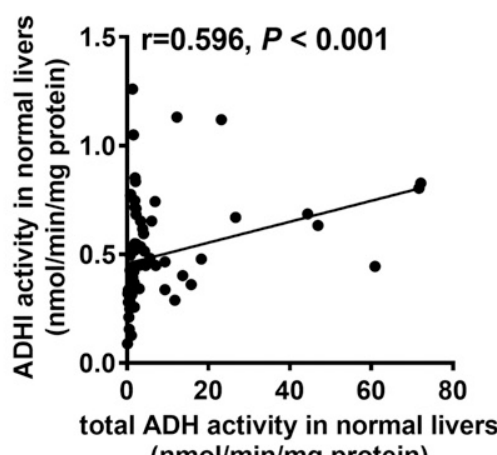

(nmol/min/mg protein)
A-2

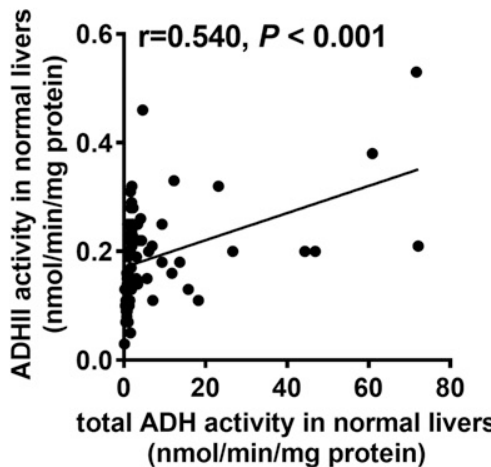

A-5

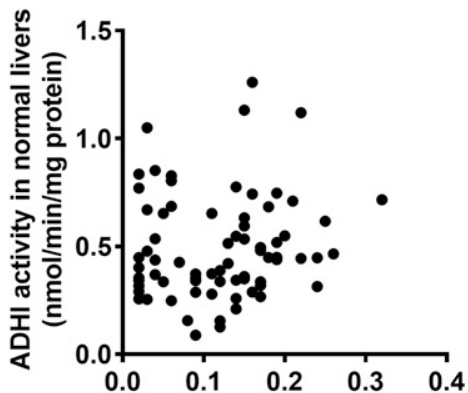

total ALDH activity in normal livers (nmol/min/mg protein)
A-3

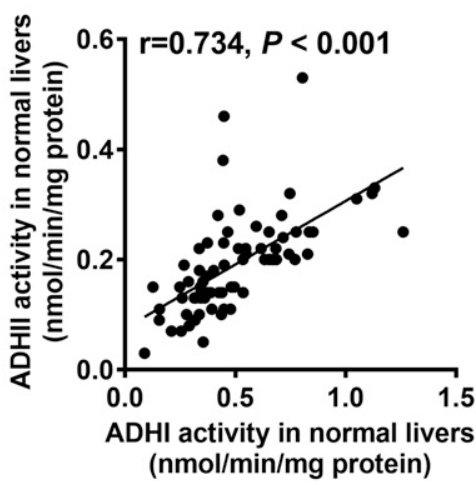

A-6

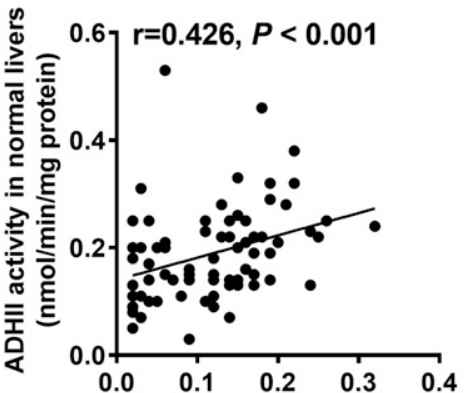

total ALDH activity in normal livers ( $\mathrm{nmol} / \mathrm{min} / \mathrm{mg}$ protein)
B-1

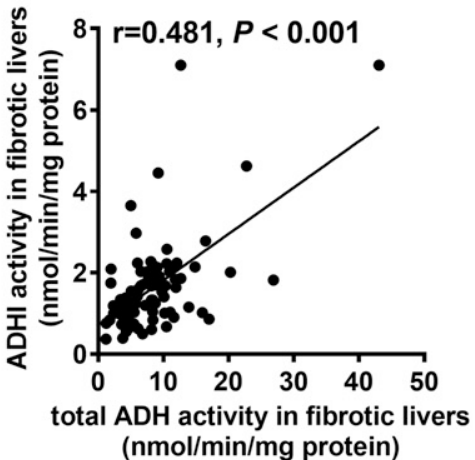

B-4



B-2

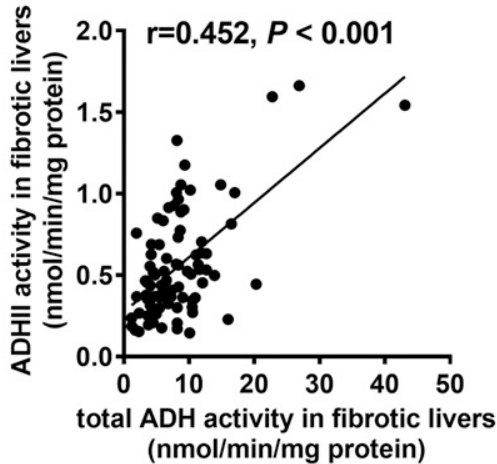

B-5

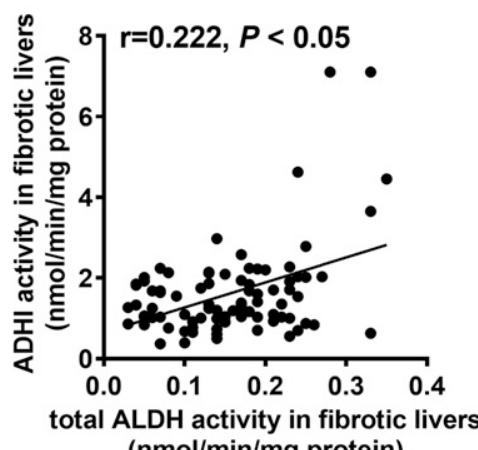

B-3

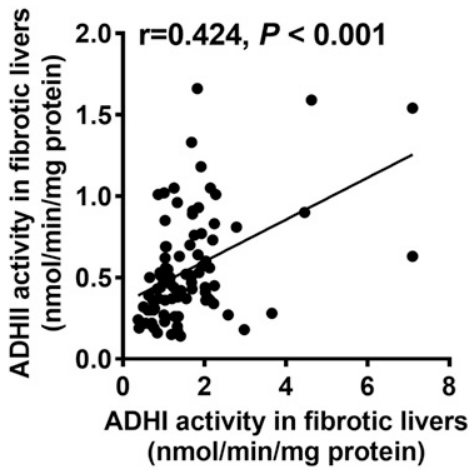

B-6



Fig. 1. Correlations among the activities of $\mathrm{ADH}, \mathrm{ADHI}, \mathrm{ADHII}$, and $\mathrm{ALDH}$ in normal (A-1 to A-6, $n=74)$ and fibrotic (B-1 to $\mathrm{B}-6, n=88)$ human livers. 
ALDH activity in fibrotic livers showed a weak correlation with ADHI $(P<0.05)$.

Correlation between the Activities of Total ADH, ADHI, ADHII, and ALDH and the Degree of Hepatofibrosis. A positive correlation was noted between the activities ADHI, ADHII, and the extent of hepatofibrosis $(P<0.01$; Fig. 2 , B and C). Total ADH activity had no relationship with the extent of hepatofibrosis $(P>0.05$ Fig. 2A). In addition, the ratio of $\mathrm{ADHI} / \mathrm{ALDH}$ was also positively correlated with the degree of hepatofibrosis $(P<0.001$; Fig. $2 \mathrm{~F})$. These results suggest that hepatofibrosis might significantly affect the activity of alcoholmetabolizing enzymes.

Positive Rate of Total ADH, ADHI, ADHII, and the Ratio of ADHI/ALDH in Fibrotic Liver Tissues. To evaluate whether the increased alcohol-metabolizing enzyme activities or ratios might be potential biomarkers, we calculated the positive rates of $\mathrm{ADH}, \mathrm{ADHI}, \mathrm{ADHII}, \mathrm{ADH} / \mathrm{ALDH}$, and ADHI/ALDH in fibrotic livers of HCC patients. Values over the P90 (percent 90) of the results for $\mathrm{ADH}, \mathrm{ADHI}$, $\mathrm{ADHII}, \mathrm{ADH} / \mathrm{ALDH}$, and ADHI/ALDH in the normal group were considered positive. The positive rates of ADHI, ADHII, and ADHI/ALDH activities in fibrotic livers from HCC patients were $84.1 \%, 77.3 \%$, and $19.3 \%$, respectively, although the positive rates of total $\mathrm{ADH}$ and $\mathrm{ADH} / \mathrm{ALDH}$ were quite low. One reason might be the substantial individual variations. The relationship between diagnostic sensitivity and specificity for $\mathrm{ADHI}$ and $\mathrm{ADHII}$ is illustrated by the receiver operator characteristics (ROC) curve, with the area under the ROC curve values a measure of diagnostic accuracy (Fig. 3), which showed that the area under the ROC curve for ADHI (0.943) and ADHII (0.912) was quite high.

The results indicated that the activities $\mathrm{ADHI}$ and ADHII were related to hepatofibrosis and could be good potential biomarkers. It was not clear, however, that the increase in $\mathrm{ADH}$ activities was a risk factor or a symptom for hepatofibrosis. To address this question, we established the fibrosis-carcinoma rat model for further study.

\section{ADH Activity in the Rat Model}

Establishment of the Fibrosis-Carcinoma Rat Model. Representative appearances of the liver in the different groups are shown in Fig. 4A. The results of H\&E and Masson staining are shown in Fig. 4, B and C. The H\&E-stained sections were quantified by the Ishak score, and the Masson-stained sections were quantified by the percentage of fibrotic area. Compared with the control group, the Ishak scores and the Masson area\% of the rats in fibrosis and HCC group were significantly increased $(P<0.001)$. No significant difference in Ishak score and Masson area\% was found between the fibrosis and HCC rats (Fig. 4, D and E). Moreover, the values of ALT and AST levels in serum were significantly increased in the model
A

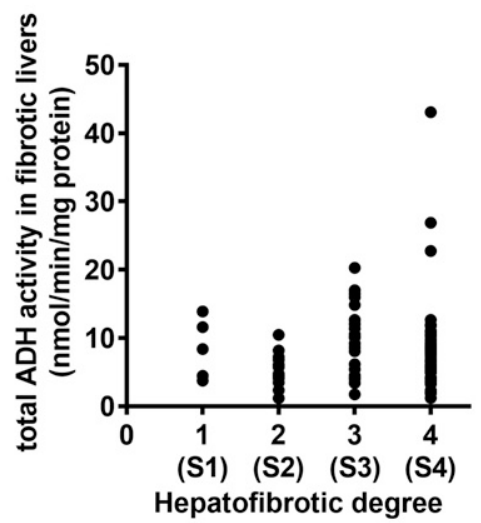

D

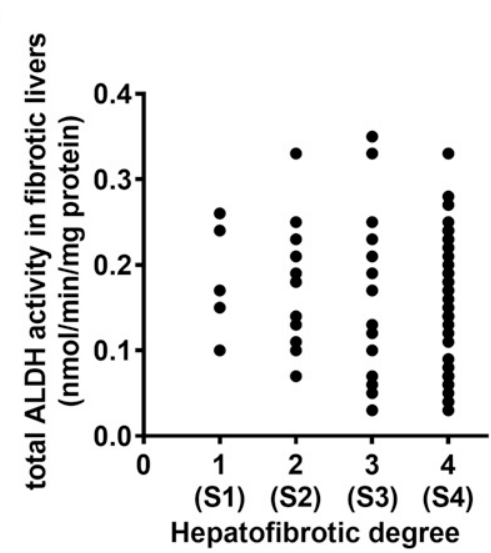

B

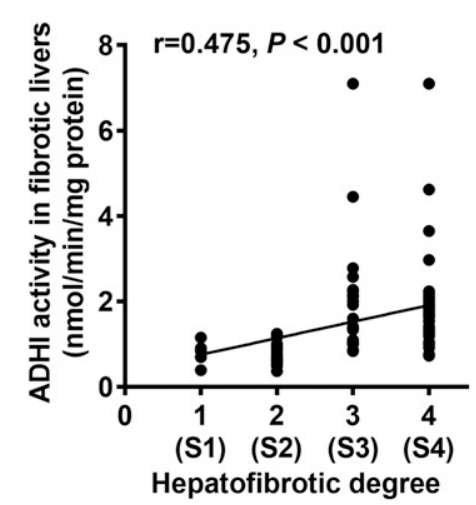

E



C

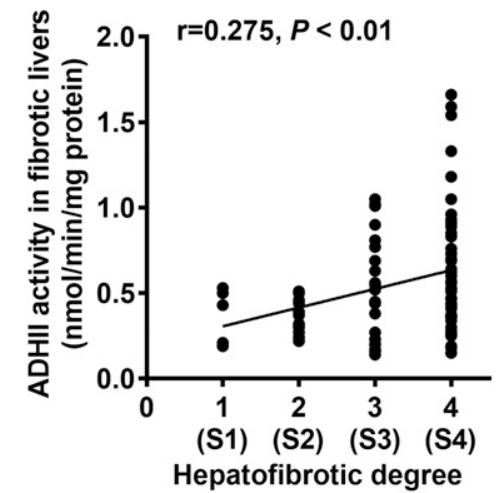

$\mathbf{F}$



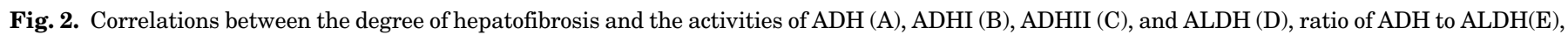

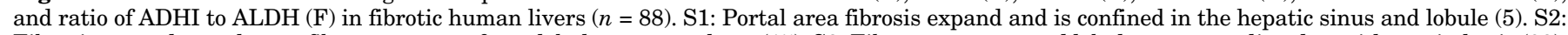

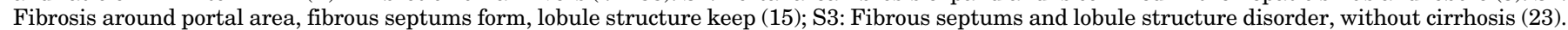
S4: Early stage cirrhosis (45). 


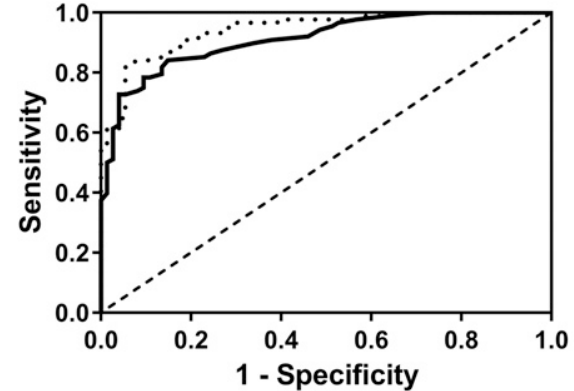

group (Fig. 4F; $P<0.001$ ) compared with controls at different times $(8,12,16$, and 19 weeks).

Evaluation of Hepatocyte Proliferation. The percentage of Ki67-positive cells and PCNA-positive cells was significantly increased in rats of the fibrosis and HCC groups compared with the control group (Fig. 5, B and C; $P<0.01$ ). Simultaneously, the hepatic GST-p-positive foci were determined. In model groups, the average densities of GST-p-positive foci were also significantly increased compared with controls (Fig. 5D; $P<0.01$ ).

Evaluation of Activation of Hepatic Stellate Cells. The expression levels of $\alpha$-SMA and collagen 1 in liver were significantly higher in rats in the fibrosis and HCC groups than in the control group (Fig. 6, $P<0.05$ ), and no significant difference was seen in the expression of $\alpha$-SMA in rats in the fibrosis and HCC groups (Fig. 6); however, the expression of
A
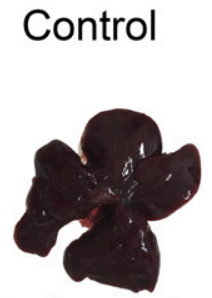

B
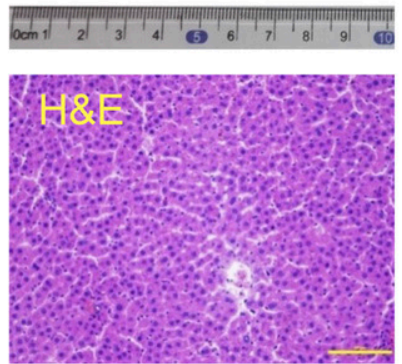

C

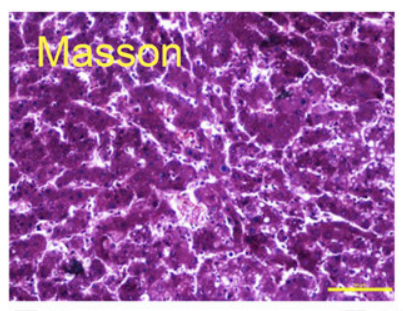

F-1

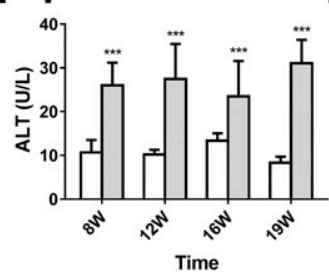

F-2
Fibrosis Group
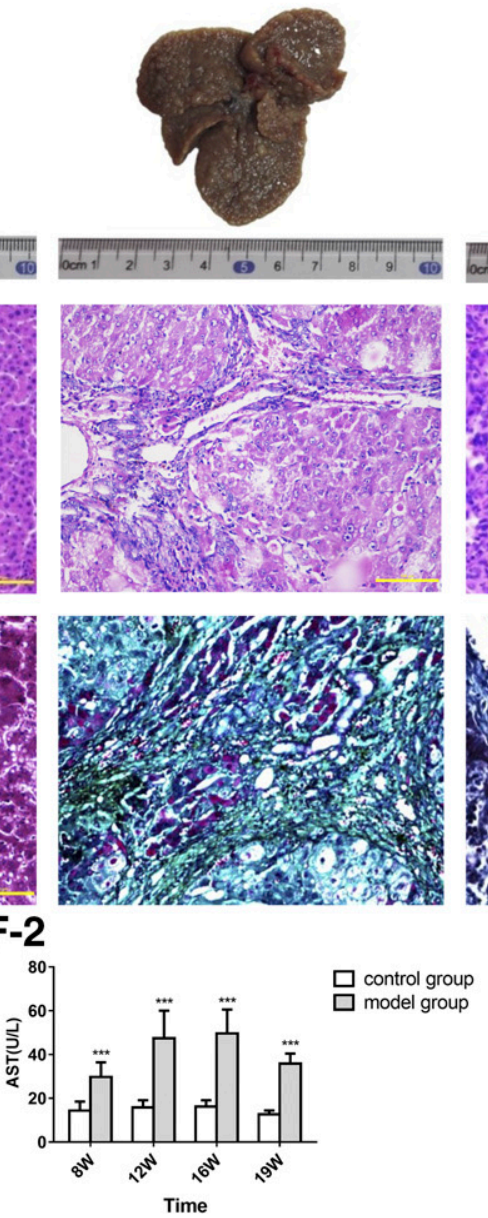

HCC Group


Fig. 4. Macroscopic and histologic hepatic changes in a fibrosis-carcinoma rat model induced by DEN. (A) Representative rat livers. (B and C) Representative H\&E (original magnification, $400 \times$ ) and Masson staining (original magnification, 400 $\times$ ) of liver tissue. (D and E) Ishak score according to H\&E staining and quantification of Masson staining area from each rat. (F) Serum ALT (F-1) and AST (F-2) levels. ***Compared with control group $P<0.001$. Data represent means \pm S.D. Control $(n=10)$ : the rats were treated with normal saline and sacrificed at 19 weeks. Fibrosis group $(n=20)$ : the rats were injected i.p. with $50 \mathrm{mg} / \mathrm{kg}$ DEN twice a week for 4 weeks, then injected i.p. with $50 \mathrm{mg} / \mathrm{kg}$ DEN once weekly to 12 weeks and sacrificed at 12 weeks. HCC group $(n=21)$ : the rats were injected i.p. with $50 \mathrm{mg} / \mathrm{kg}$ DEN twice weekly for 4 weeks, then injected i.p. with $50 \mathrm{mg} / \mathrm{kg}$ DEN once a week to 14 weeks and sacrificed at 19 weeks. 
A
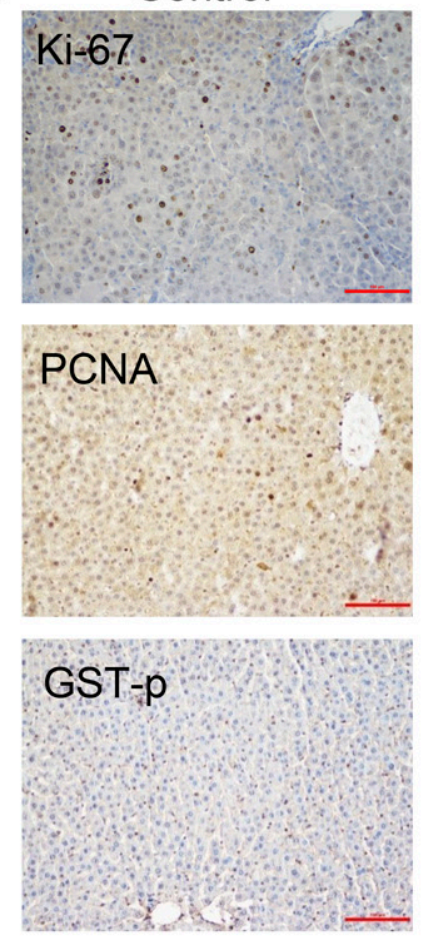

Fibrosis Group
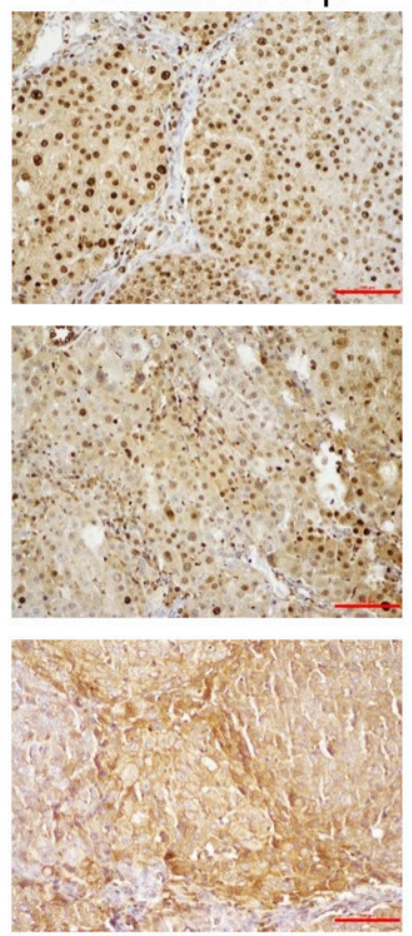
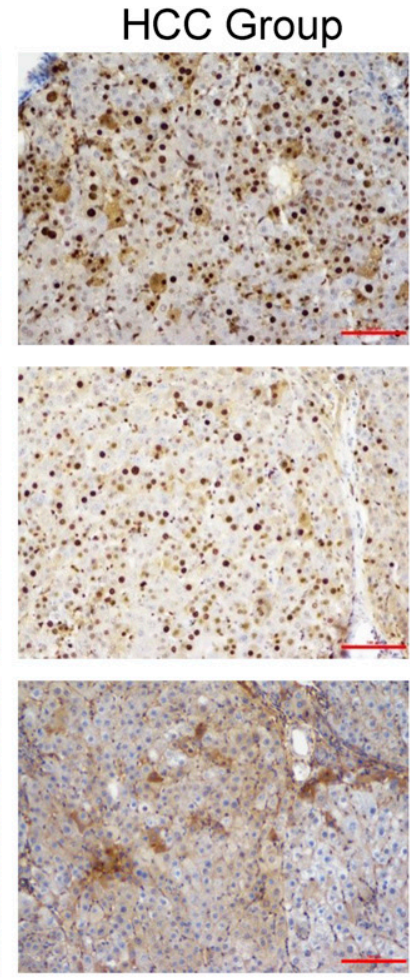

B
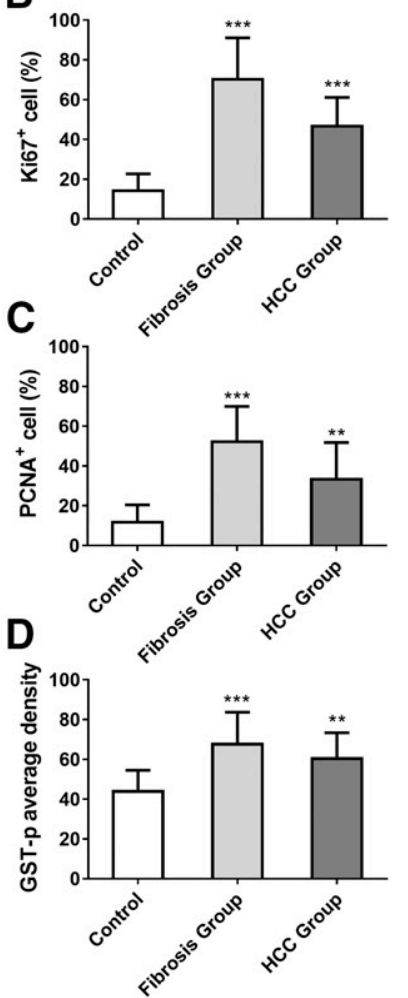

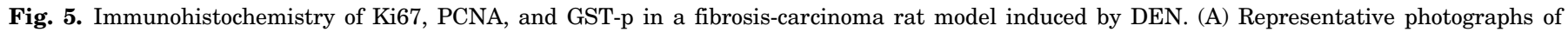

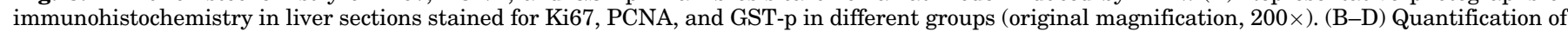



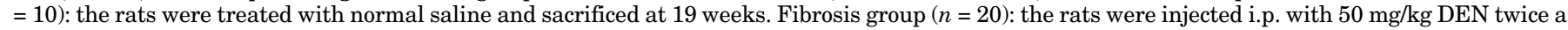



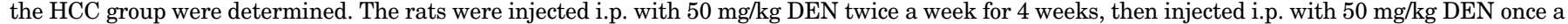
week to 14 weeks and sacrificed at 19 weeks.

collagen 1 was significantly greater in HCC group than in the fibrosis group $(P<0.01)$.

Alteration of ADH Activity in a Rat Model during the Progression of HCC Induced by DEN. We measured the activities of $\mathrm{ADH}$ in the serum and liver. Compared with the control group, the activity of $\mathrm{ADH}$ in the serum of rats treated with DEN was significantly increased at the 16 th week $(24.21 \pm$ $9.86 \mathrm{U} / \mathrm{ml})$ and the 19 th week $(24.56 \pm 9.65 \mathrm{U} / \mathrm{ml})$, with no significant change at 8 th and 12 th weeks (Fig. 7A, $P>0.05$ ).

Compared with the control group $(3.41 \pm 1.12 \mathrm{U} / \mathrm{mg}$ protein), the $\mathrm{ADH}$ activity in the livers of rats treated with $\mathrm{DEN}$ was significantly increased in rats in the fibrosis $(4.50 \pm$
A

a-SMA
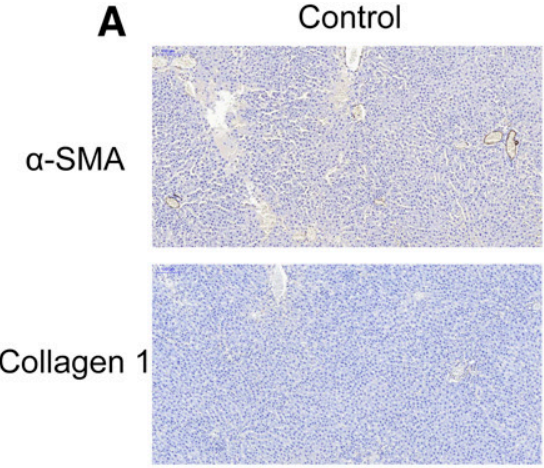

Fibrosis Group
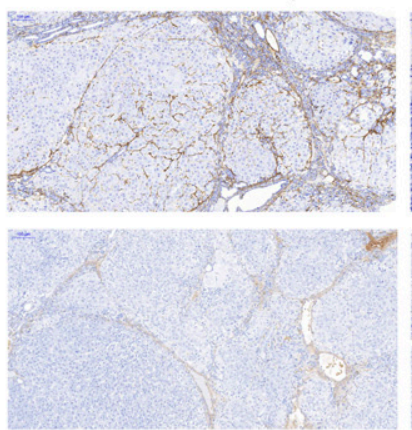

HCC Group
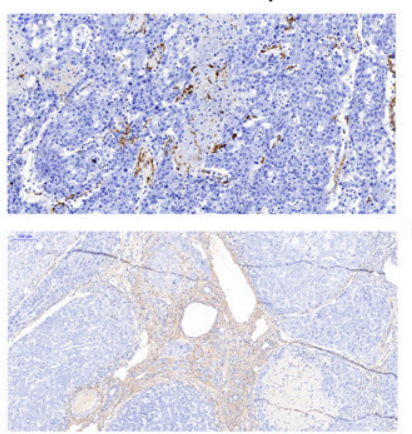

B


Fig. 6. Immunohistochemistry of $\alpha$-SMA and collagen 1 in a fibrosis-carcinoma rat model induced by DEN. (A) Representative photographs of immunohistochemistry of liver sections stained for $\alpha$-SMA (original magnification, $100 \times$ ) and collagen $1 \alpha$ (original magnification, $100 \times$ ). (B and C) $\mathrm{H}$-score of $\alpha$-SMA and collagen $1 \alpha$ in different groups. *Versus control, $P<0.05$; *Versus control, $P<0.01$; ***Versus control, $P<0.001$; \#Versus fibrosis group, $P<0.05$. Data represent means \pm S.D. Control $(n=8)$ : rats were treated with normal saline and sacrificed at 19 weeks. Fibrosis group $(n=$ 10): 10 rats were chosen randomly from the fibrosis group. The rats were injected i.p. with $50 \mathrm{mg} / \mathrm{kg} \mathrm{DEN}$ twice a week for 4 weeks, then injected i.p. with $50 \mathrm{mg} / \mathrm{kg}$ DEN once a week to 12 weeks and sacrificed at 12 weeks. HCC group $(n=12): 12$ rats were chosen at random from the HCC group. The rats were injected i.p. with $50 \mathrm{mg} / \mathrm{kg}$ DEN twice a week for 4 weeks, then injected i.p. with $50 \mathrm{mg} / \mathrm{kg}$ DEN once a week to 14 weeks and sacrificed at 19 weeks. 

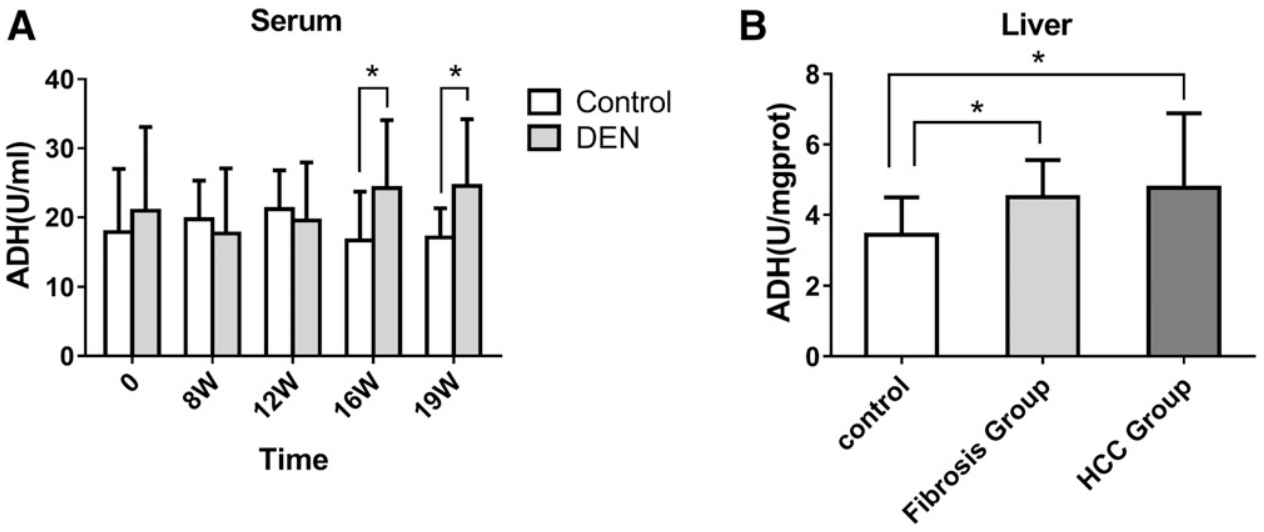

Fig. 7. Activities of $\mathrm{ADH}$ in serum (A) and liver tissues (B) in a fibrosis-carcinoma rat model induced by DEN. *Versus control, $P<0.05$. Date represent means \pm S.D. Control $(n=10)$ : the rats were treated with normal saline and sacrificed at 19 weeks. Fibrosis group $(n=20)$ : the rats were injected i.p. with $50 \mathrm{mg} / \mathrm{kg}$ DEN twice a week for 4 weeks, then injected intraperitoneally with $50 \mathrm{mg} / \mathrm{kg}$ DEN once a week to 12 weeks and sacrificed at 12 weeks. HCC group $(n=21)$ : the rats were injected i.p. with $50 \mathrm{mg} / \mathrm{kg}$ DEN twice weekly for 4 weeks and then injected i.p. with $50 \mathrm{mg} / \mathrm{kg}$ DEN once a week to 14 weeks and sacrificed at 19 weeks.

$1.05 \mathrm{U} / \mathrm{mg}$ protein) and in the HCC groups $(4.77 \pm 2.11 \mathrm{U} / \mathrm{mg}$ protein) (Fig. 7B, $P<0.05$ ). These results suggest that the activity of $\mathrm{ADH}$ in livers at the fibrotic stage is greater than that in controls, but from hepatofibrosis to HCC, no significant change in $\mathrm{ADH}$ activity was seen. Given that the activity level of $\mathrm{ADH}$ was higher in fibrotic livers from HCC patients than that in controls, we conclude that the activities ADHI and ADHII might be good potential biomarkers for hepatofibrosis.

Relationship between ADH Activity and Liver Injury or Hepatocyte Proliferation in Rats. To confirm that high $\mathrm{ADH}$ activity is a risk factor for hepatofibrosis or HCC, we determined the innate activity of $\mathrm{ADH}$ in serum. A positive correlation was found between the innate activity of $\mathrm{ADH}$ ( 0 week) in the serum of rats in the fibrosis group and the extent of fibrosis as measured by the four indexes (i.e., Masson area $\%, \mathrm{Ki}^{+} \%$, $\mathrm{PCNA}^{+} \%$, GST-p average density), and the correlation coefficients were $0.453,0.512,0.457,0.450$, respectively (Fig. 8A; $P<0.05$ ). No correlation was established between the innate $\mathrm{ADH}$ activity of rats in the $\mathrm{HCC}$ group and indices reflecting hepatic lesions ( $P>0.05$; data not shown). In addition, no significant correlation was found between the innate activity of $\mathrm{ADH}$ and the expression of $\alpha$-SMA and collagen 1 in rats of both the fibrosis and HCC groups (data not shown). The results indicate that rats with higher $\mathrm{ADH}$ activity levels were more prone to hepatofibrosis, which suggests that the high activity level might be a risk factor for hepatofibrosis.

In addition, $\mathrm{ADH}$ activity in the liver of rats in the $\mathrm{HCC}$ group correlated with the five indexes reflecting hepatic lesions (liver weight/body weight, nodule number, largest diameter of nodule, cumulative diameter of nodule, $\mathrm{Ki}_{67}^{+} \%$ ), and the correlation coefficients were $0.567,0.499,0.438,0.626$, 0.506, respectively (Fig. 8B; $P<0.05$ ).

\section{Discussion}

This study provides the physiologic values of $\mathrm{ADH}$ and ALDH activities along with the ratio $\mathrm{ADH}$ to $\mathrm{ALDH}$ in human normal livers. Results showed that $\mathrm{ADH}$ activity was significantly greater in fibrotic livers. The positive rates of $\mathrm{ADHI}$ and $\mathrm{ADHII}$ were greater than $70 \%$, and the area under ROC curve was greater than 0.9 . The results of the animal experiments further indicated that $\mathrm{ADH}$ activity in livers was greater at the fibrotic stage and that there was no significant difference in that measure between fibrosis and the HCC stage. Moreover, significant correlation was found between the innate activity of $\mathrm{ADH}$ in serum and the extent of fibrosis as indicated by Masson area $\%, \mathrm{Ki}^{+} \%, \mathrm{PCNA}^{+} \%$, and GST-p average density at fibrosis stage. We conclude that elevated activity of $\mathrm{ADH}$ may be a risk factor for hepatofibrosis. Moreover, $\mathrm{ADH}$ activity can also be a biomarker for hepatofibrosis.

Drinking alcohol has been recognized as a major risk factor for hepatofibrosis and HCC, together with hepatitis B virus and hepatitis $\mathrm{C}$ virus infection (Jelski et al., 2008b). It is accepted that ethanol is metabolized to acetaldehyde by $\mathrm{ADH}$ and that acetaldehyde is oxidized by ALDH to acetic acid in the liver. Acetaldehyde, the intermediate product of ethanol, is toxic. Therefore, not only $\mathrm{ADH}$ and $\mathrm{ALDH}$, but also the ratio of $\mathrm{ADH}$ and $\mathrm{ALDH}$, are very important, especially ADHI/ALDH, owing to ADHI being mainly responsible for ethanol metabolism. To date, there have been no reports on the physiologic values or reference ranges for the activities of the various isozymes of $\mathrm{ADH}$. Hence, determination of the activity level and individual variations in $\mathrm{ADH}$ activity over a large number of samples is needed to provide reliable physiologic parameters for in vivo and in vitro research.

Our study was first to report the physiologic values of $\mathrm{ADH}$ activity, $\mathrm{ALDH}$ activity, and the ratio of $\mathrm{ADHI}$ and $\mathrm{ALDH}$ in 74 normal human liver samples and found that they vary by 14- to 809-fold in different individuals. Dannenberg et al. (2006) reported that the expression of ADHI in HepG2 cells may be regulated by an epigenetic mechanism, such as methylation and histone deacetylation. We shall explore the factors involved in the activities of $\mathrm{ADH}$ in a future study.

Our results show that all $\mathrm{ADH}$ isozyme activities in fibrotic livers were significantly greater than that in normal livers. The positive rates of both $\mathrm{ADHI}$ and $\mathrm{ADHII}$ were greater than $70 \%$. Most HCCs develop from hepatofibrosis, and the potential curative treatment options are limited (Kimhofer et al., 2015), so it is quite important to look for biomarkers for hepatofibrosis. It has been reported that some substances, such as angiopoietin-like protein 2 or serum biglycan, can be biomarkers for liver fibrosis, but the area under the ROC curve for the reports were lower than 0.9 (Ciftciler et al., 2017; Deng et al., 2017). In this study, the area under the ROC curve for $\mathrm{ADHI}$ and $\mathrm{ADHII}$ was greater than 0.9. Moreover, the value of $\mathrm{ADHI}$ showed good correlation with the degree of hepatic fibrosis. As a result, $\mathrm{ADHI}$ and ADHII could be potential biomarkers for hepatofibrosis. It is well known that although some substances can be used as a biomarker for some diseases, most cannot be considered a risk factor. In this study, 




ADH activity in plasma at 0 week of Fibrosis Group (U/ml)



$\mathrm{ADH}$ activity in plasma at 0 week of Fibrosis Group (U/ml)

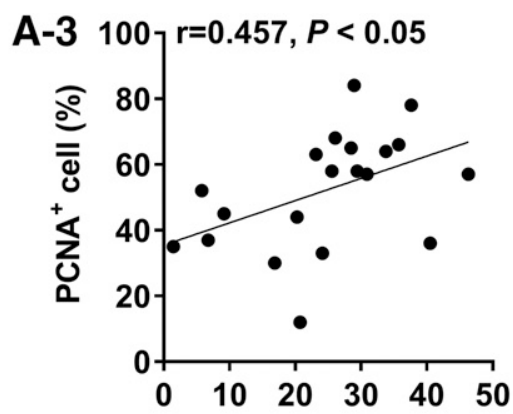

ADH activity in plasma at 0 week of Fibrosis Group (U/ml)

\section{A-4}

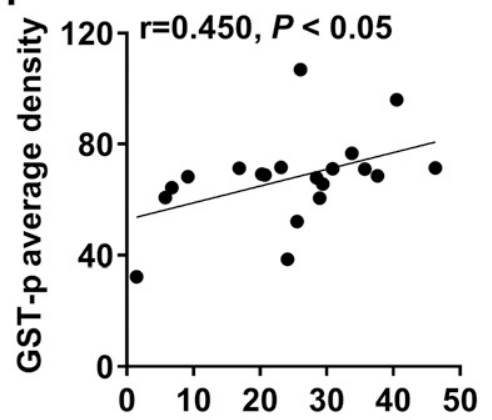

ADH activity in plasma at 0 week of Fibrosis Group (U/ml)
B-1

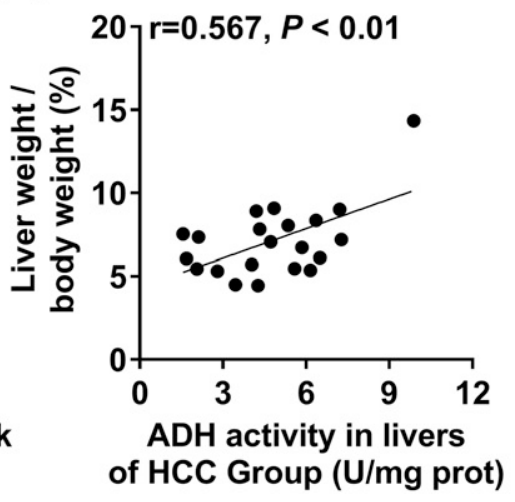

B-2

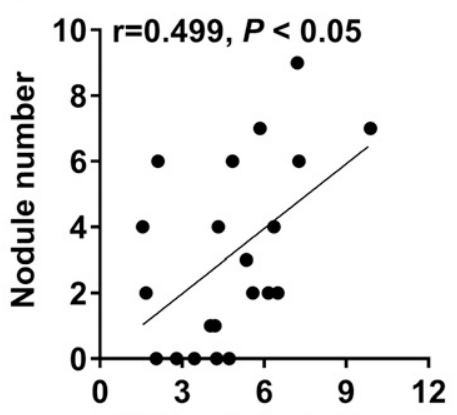

ADH activity in livers of HCC Group (U/mg prot)
B-3

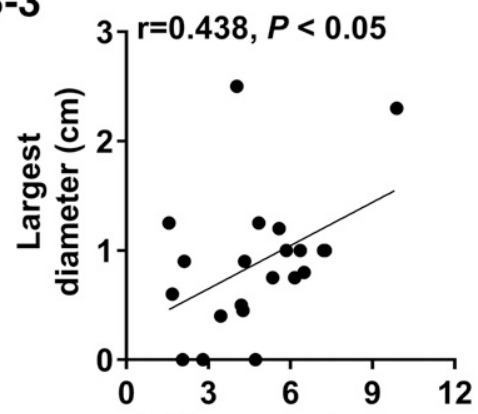

ADH activity in livers of HCC Group (U/mg prot)
B-4



ADH activity in livers of HCC Group (U/mg prot)
B-5

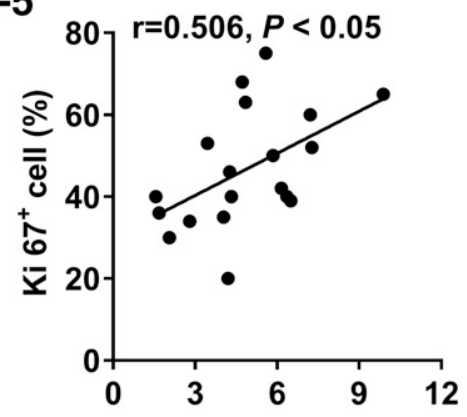

ADH activity in livers of HCC Group (U/mg prot)

Fig. 8. Correlations between index of hepatic lesions and ADH activity in a fibrosis-carcinoma rat model induced by DEN. (A-1 to A-4) Correlations between liver injury-related indicators and $\mathrm{ADH}$ activity in serum at week 0 of the fibrosis group. (B-1 to B-5) Correlations between liver injury-related indicators and $\mathrm{ADH}$ activity in rat livers from the $\mathrm{HCC}$ group. Fibrosis group $(n=20)$ : the rats were injected i.p. with $50 \mathrm{mg} / \mathrm{kg} \mathrm{DEN}$ twice a week for 4 weeks, then injected i.p. with $50 \mathrm{mg} / \mathrm{kg}$ DEN once a week to 12 weeks and sacrificed at 12 weeks. HCC group $(n=21)$ : the rats were injected i.p. with $50 \mathrm{mg} / \mathrm{kg}$ DEN twice weekly for 4 weeks, then injected i.p. with $50 \mathrm{mg} / \mathrm{kg}$ DEN once weekly to 14 weeks and sacrificed at 19 weeks. The Ki67 of 19 rats in HCC group was determined.

we found that the $\mathrm{ADH}$ activity was not only a biomarker but also a risk factor for hepatofibrosis.

We analyzed the correlations among $\mathrm{ADH}$ isozymes and $\mathrm{ALDH}$ and found significant correlation among total $\mathrm{ADH}$, ADHI, and ADHII in normal and fibrotic livers. Amino acid sequence identity between $\mathrm{ADH}$ isozymes was at the $60 \%$ level (Jelski and Szmitkowski, 2008). The marked correlations among $\mathrm{ADH}$ isozyme activities provided clear evidence for the coregulation of $\mathrm{ADH}$ forms. In addition, the correlations between $\mathrm{ADH}$ isozymes and $\mathrm{ALDH}$ in fibrotic liver were different from that in normal liver. In the normal liver, the activity of ALDH had obvious correlations with ADHII.
In fibrotic livers from $\mathrm{HCC}$, it was changed to $\mathrm{ADHI}$, which is mainly responsible for metabolism of ethanol. The results suggested that the liver disease significantly affected the activity of the alcohol-metabolizing enzyme.

To further confirm that higher activity level is a symptom or a susceptibility factor for hepatofibrosis or HCC, we established a hepatic fibrosis-carcinoma rat model induced by DEN. Our results also found that rats treated with DEN at 12 and 19 weeks showed the characteristic histologic changes of fibrosis and HCC, respectively. We also measured some indices of liver injury, including Masson area $\%, \mathrm{Ki}^{+} \%$, $\mathrm{PCNA}^{+} \%$, and GST-p average density; we found that the innate activity of $\mathrm{ADH}$ in 
serum showed moderate correlations with four indices in the fibrosis stage but not in the HCC stage. Thus, the increase in innate activity of $\mathrm{ADH}$ may be a susceptibility factor for hepatic fibrosis but not for HCC. Recent research showed the lack of ADHIII in hepatic stellate cells and natural killer cells to be associated with inhibition of hepatofibrosis (Yi et al., 2014); these findings are similar to our results. In addition, our results indicated that the expression levels of $\alpha$-SMA and collagen 1 were significantly higher in rats in the fibrosis and HCC groups than those in the control group, similar to the results of Ding et al. (2017); however, no correlation was found between $\mathrm{ADH}$ activity and content of $\alpha$-SMA and collagen 1 . The detailed mechanism has not been established and should be further explored.

In summary, total $\mathrm{ADH}, \mathrm{ADH} \mathrm{I}$, and $\mathrm{ADHII}$ activities were significantly greater in human fibrotic livers than in normal livers. In a rat liver model, a causal relationship was found between the innate activity of $\mathrm{ADH}$ in serum and hepatofibrosis. The results suggest that the higher activity level of $\mathrm{ADH}$ may be a risk factor for hepatic fibrosis, and it is possible for $\mathrm{ADH}$ to be viewed as a target for hepatic fibrogenesis.

\section{Authorship Contributions}

Participated in research design: Qiao.

Conducted experiments: N. Gao, J. Li, Qi, Z. Wang, G.-J. Wang, J. Gao.

Performed data analysis: N. Gao, J. Li, M.-R. Li.

Wrote or contributed to the writing of the manuscript: N. Gao, J. Li.

\section{References}

Bataller R, Paik YH, Lindquist JN, Lemasters JJ, and Brenner DA (2004) Hepatitis $\mathrm{C}$ virus core and nonstructural proteins induce fibrogenic effects in hepatic stellate cells. Gastroenterology 126:529-540.

Beck M, Schirmacher P, and Singer S (2017) Alterations of the nuclear transport system in hepatocellular carcinoma-new basis for therapeutic strategies. J Hepatol 67:1051-1061.

Ciftciler R, Ozenirler S, Yucel AA, Cengiz M, Erkan G, Buyukdemirci E, Sönmez C, and Esendagl GY (2017) The importance of serum biglycan levels as a fibrosis marker in patients with chronic hepatitis B. J Clin Lab Anal 31:e22109.

Dannenberg LO, Chen HJ, Tian H, and Edenberg HJ (2006) Differential regulation of the alcohol dehydrogenase $1 \mathrm{~B}(\mathrm{ADH} 1 \mathrm{~B})$ and $\mathrm{ADH} 1 \mathrm{C}$ genes by DNA methylation and histone deacetylation. Alcohol Clin Exp Res 30:928-937.

Deng Y, Zhao H, Zhou J, Yan L, and Wang G; China HepB-Related Fibrosis Assessment Research Group (2017) Angiopoietin-like protein as a novel marker for liver fibrosis in chronic hepatitis B patients with normal to minimally raised ALT. BMC Infect Dis 17:650.

Ding YF, Wu ZH, Wei YJ, Shu L, and Peng YR (2017) Hepatic inflammation-fibrosis-cancer axis in the rat hepatocellular carcinoma induced by diethylnitrosamine. J Cancer Res Clin Oncol 143:821-834.

Gao J, Wang GJ, Wang Z, Gao N, Li J, Zhang YF, Zhou J, Zhang HX, Wen Q, Jin H, et al. (2017) High CYP2E1 activity correlates with hepatofibrogenesis induced by nitrosamines. Oncotarget 8:112199-112210.

Gao N, Tian X, Fang Y, Zhou J, Zhang H, Wen Q, Jia L, Gao J, Sun B, Wei J, Zhang Y, Cui M, and Qiao H (2016) Gene polymorphisms and contents of cytochrome P450s have only limited effects on metabolic activities in human liver microsomes. Eur $J$ Pharmaceut Sci 92:86-97.

Ishak K, Baptista A, Bianchi L, Callea F, De Groote J, Gudat F, Denk H, Desmet V, Korb G, MacSween RN, et al. (1995) Histological grading and staging of chronic hepatitis. J Hepatol 22:696-699.

Jelski W, Chrostek L, and Szmitkowski M (2007) The activity of class I, II, III, and IV of alcohol dehydrogenase isoenzymes and aldehyde dehydrogenase in pancreatic cancer. Pancreas 35:142-146.
Jelski W, Laniewska-Dunaj M, Orywal K, Kochanowicz J, Rutkowski R, and Szmitkowski M (2014) The activity of alcohol dehydrogenase (ADH) isoenzymes and aldehyde dehydrogenase (ALDH) in the sera of patients with brain cancer. Neurochem Res 39:2313-2318.

Jelski W and Szmitkowski M (2008) Alcohol dehydrogenase (ADH) and aldehyde dehydrogenase (ALDH) in the cancer diseases. Clin Chim Acta 395:1-5.

Jelski W, Zalewski B, and Szmitkowski M (2008a) The activity of class I, II, III, and IV alcohol dehydrogenase (ADH) isoenzymes and aldehyde dehydrogenase (ALDH) in liver cancer. Dig Dis Sci 53:2550-2555

Jelski W, Zalewski B, and Szmitkowski M (2008b) Alcohol dehydrogenase (ADH) isoenzymes and aldehyde dehydrogenase (ALDH) activity in the sera of patients with liver cancer. J Clin Lab Anal 22:204-209.

Jelski W, Zalewski B, and Szmitkowski M (2008c) Alcohol dehydrogenase (ADH) isoenzymes and aldehyde dehydrogenase (ALDH) activity in the sera of patients with pancreatic cancer. Dig Dis Sci 53:2276-2280.

Kimhofer T, Fye H, Taylor-Robinson S, Thursz M, and Holmes E (2015) Proteomic and metabonomic biomarkers for hepatocellular carcinoma: a comprehensive review. $B r$ J Cancer 112:1141-1156.

Kitahara A, Satoh K, Nishimura K, Ishikawa T, Ruike K, Sato K, Tsuda H, and Ito N (1984) Changes in molecular forms of rat hepatic glutathione S-transferase during chemical hepatocarcinogenesis. Cancer Res 44:2698-2703.

Laniewska-Dunaj M, Jelski W, Orywal K, Kochanowicz J, Rutkowski R, and Szmitkowski M (2013) The activity of class I, II, III and IV of alcohol dehydrogenase $(\mathrm{ADH})$ isoenzymes and aldehyde dehydrogenase (ALDH) in brain cancer. Neurochem Res 38:1517-1521.

Lieber CS (1997) Role of oxidative stress and antioxidant therapy in alcoholic and nonalcoholic liver diseases. Adv Pharmacol 38:601-628.

Maly IP, Toranelli M, and Sasse D (1999) Distribution of alcohol dehydrogenase isoenzymes in the human liver acinus. Histochem Cell Biol 111:391-397.

Marshall VJ, Ramchandani VA, Kalu N, Kwagyan J, Scott DM, Ferguson CL, and Taylor RE (2014) Evaluation of the influence of alcohol dehydrogenase polymorphisms on alcohol elimination rates in African Americans. Alcohol Clin Exp Res 38:51-59.

Orywal K, Jelski W, Werel T, and Szmitkowski M (2015) The activity of class I, II, III and IV alcohol dehydrogenase isoenzymes and aldehyde dehydrogenase in renal cell carcinoma. Exp Mol Pathol 98:403-406.

Orywal K, Jelski W, Werel T, and Szmitkowski M (2016) The diagnostic significance of serum alcohol dehydrogenase isoenzymes and aldehyde dehydrogenase activity in renal cell cancer patients. Exp Mol Pathol 100:416-420.

Sato K, Kitahara A, Satoh K, Ishikawa T, Tatematsu M, and Ito N (1984) The placental form of glutathione S-transferase as a new marker protein for preneoplasia in rat chemical hepatocarcinogenesis. Gan 75:199-202.

Skurský L, Kovár J, and Stachová M (1979) A sensitive photometric assay for alcohol dehydrogenase activity in blood serum. Anal Biochem 99:65-71.

Song B-J, Akbar M, Jo I, Hardwick JP, and Abdelmegeed MA (2015) Translational implications of the alcohol-metabolizing enzymes, including cytochrome P450-2E1, in alcoholic and nonalcoholic liver disease. Adv Pharmacol 74:303-372.

Wheeler MD, Kono H, Yin M, Nakagami M, Uesugi T, Arteel GE, Gäbele E, Rusyn I, Yamashina S, Froh M, et al. (2001) The role of Kupffer cell oxidant production in early ethanol-induced liver disease. Free Radic Biol Med 31:1544-1549.

Wierzchowski J, Dafeldecker WP, Holmquist B, and Vallee BL (1989) Fluorometric assays for isozymes of human alcohol dehydrogenase. Anal Biochem 178:57-62.

Yeo W, Chan SL, Mo FK, Chu CM, Hui JW, Tong JH, Chan AW, Koh J, Hui EP, Loong H, et al. (2015) Phase I/II study of temsirolimus for patients with unresectable hepatocellular carcinoma (HCC)—a correlative study to explore potential biomarkers for response. BMC Cancer 15:395

Yi HS, Lee YS, Byun JS, Seo W, Jeong JM, Park O, Duester G, Haseba T, Kim SC Park KG, et al. (2014) Alcohol dehydrogenase III exacerbates liver fibrosis by enhancing stellate cell activation and suppressing natural killer cells in mice. Hepatology 60:1044-1053.

Yu HS, Oyama T, Isse T, Kitagawa K, Pham TT, Tanaka M, and Kawamoto T (2010) Formation of acetaldehyde-derived DNA adducts due to alcohol exposure. Chem Biol Interact 188:367-375.

Zakhari S and Li TK (2007) Determinants of alcohol use and abuse: impact of quantity and frequency patterns on liver disease. Hepatology 46:2032-2039.

Zhou J, Wen Q, Li SF, Zhang YF, Gao N, Tian X, Fang Y, Gao J, Cui MZ, He XP, et al. (2016) Significant change of cytochrome P450s activities in patients with hepatocellular carcinoma. Oncotarget 7:50612-50623.

Address correspondence to: Hai-Ling Qiao, Institute of Clinical Pharmacology, School of Medicine, Zhengzhou University, 40 Daxue Road, Zhengzhou, 450052, China. E-mail: qiaohl@zzu.edu.cn 